\title{
The Time-Driven Activity-Based Costing Model for a Small Startup in Indonesia
}

\author{
Dewi Fitriasari ${ }^{1 *}$; Naoko Kawahara ${ }^{2}$ \\ ${ }^{1}$ International Accounting \& Finance Program, Accounting Department, \\ Faculty of Economics \& Communication, Bina Nusantara University \\ Jln. K. H. Syahdan No. 9, Jakarta Barat 11480, Indonesia \\ ${ }^{2}$ Accounting Department, Kindai University \\ 3-4-1 Kowakae, Higashiosaka, Osaka 577-8502, Japan \\ 1dditriasari@binus.edu; ${ }^{2 n k a w a h a r a @ b u s . k i n d a i . a c . j p ~}$
}

Received: $6^{\text {th }}$ August $2019 /$ Revised: $30^{\text {th }}$ January $2020 /$ Accepted: $5^{\text {th }}$ May 2020

How to Cite: Fitriasari, D., \& Kawahara, N. (2020). The Time-Driven Activity-Based Costing Model for a Small Startup in Indonesia. Binus Business Review, 11(2), 141-148. https://doi.org/10.21512/bbr.v11i2.5869

\begin{abstract}
The research proposed a Time-Driven Activity-Based Costing (TDABC) model for cost and human capital analysis in a small startup in Indonesia. TDABC discussed and illustrated the integration of capabilities into cost and performance in startups. The researchers applied a qualitative simulation method. The data were taken from actual regulatory data of wage and salary from the local government of Jakarta. The other data were simulated data based on a software development process for a small startup. The result indicates that the TDABC can assist the company to trace its performance and costs. Additional factors in implementing the costing system are provided for further research and practical considerations in adopting the costing system.
\end{abstract}

Keywords: Time-Driven Activity-Based Costing model, small startup, startup performance, startup cost

\section{INTRODUCTION}

Activity-Based Costing ( $\mathrm{ABC})$ is a method that requires a company to detail its cost drivers based on value-added activities. The details required in establishing $\mathrm{ABC}$ can be a burden for a company. It starts with the identification of activities and spends a long time finishing each activity. This condition was detected as far as 1995 in the thousand most significant companies in United Kingdom (Innes \& Mitchell, 1995). Since then, the research of ABC has aimed to explore other factors that can assist the adoption of the costing system. For example, Malmi (1999) conducted an interview-based study to explore the diffusion of $\mathrm{ABC}$ as a management accounting innovation in Finnish companies and found that external factors in adopting organization are more significant than the internal ones. This prior research contributes to knowledge on factors that drive a company to adopt $\mathrm{ABC}$ despite its complex process.

These external and internal factors for adopting $\mathrm{ABC}$ attract further research on the United Kingdom's largest companies. Innes, Mitchell, and Sinclair (2000) considered the internal versus external factor effects on $\mathrm{ABC}$ implementation in the largest companies in United Kingdom. It was a continuation of their research in 1995. They found that external factors were inconclusively important in the surveyed companies. Additionally, the survey results indicated that positive versus negative internal perspectives of adopters and non-adopters of $\mathrm{ABC}$ were significant factors in the implementation of $\mathrm{ABC}$. The survey participants eventually decided not to use $\mathrm{ABC}$, while non-adopters reportedly had a negative perspective on $\mathrm{ABC}$ as they saw no significance of $\mathrm{ABC}$ for decision-making. $\mathrm{ABC}$ for them contained imprecision in the system of cost allocation. This specific finding was an indicator of a rebuff of the notion of $\mathrm{ABC}$ for decision-making related to pricing, product portfolios, and making or buying decisions, as stated by Bromwich and Hong (1999), Ittner (1999), and Johnson and Brennan (2018). At this stage, $A B C$ needed to answer the challenges in terms of its benefits and implementation for business.

In 1997, a modification on the measurement of ABC called Time-Driven Activity-Based Costing (TDABC) was introduced. TDABC is a modified 
$\mathrm{ABC}$ method in terms of the measurement base for resource capacities used in activities that drive costs (Kaplan \& Anderson, 2007). This modification aims to simplify $\mathrm{ABC}$ by differentiating between theoretical and practical resource capacities in terms of time instead of directly going to time spent per activity and detailed activities done at the initial stage of ABC.

After knowing the general practical capacities, the numbers are adopted as the total capacities are available. The numbers representing the total available capacities will be divided into work that must be done by budgeting activities. Then, the resulting activity rates will be a multiplication factor for the actual level of activity. The result will be TDABC costs (Kaplan $\&$ Anderson, 2007). The modification that starts with general capacities is divided into the budget. It simplifies the previous requirements for specific activities in the initial stage of $\mathrm{ABC}$ that previously complicates the $\mathrm{ABC}$ adoption.

Since its introduction, TDABC has been studied for its benefits and implementations in different settings. In some case studies, TDABC is advantageous for setting value-added time-tracing in companies for customer-profit analysis and efficiency performance (Afonso \& Santana, 2016; Jeong \& Ahn, 2015). In a large distribution company, TDABC is useful for routes profitability resulting in a more effective transport functionality (Martínez-Vivar, SánchezRodríguez, Pérez-Campdesuñer, \& García-Vidal, 2018). The standardized time setting in a TDABC can yield similar costs as non-TDABC (Ratnatunga, Michael, \& Balachandran, 2012). Nevertheless, actual time-tracing is an important benefit in a TDABC setting.

The proposed models in logistics areas based on TDABC are also flourishing. For example, Varila, Seppänen, \& Suomala (2007) suggested using accounting technology to record the actual time spent for determining the $\mathrm{ABC}$ cost drivers related to time using regression models. Ratnatunga et al. (2012) also agreed that this technology-integrated model of TDABC supported the need for actual timetracing. Similarly, Hoffman and Bosshard (2017) used technology in tracing time for TDABC in supply chain management. Next, Afonso and Santana (2016) proposed a TDABC model based on internal logistics and distribution activities with margin analysis for route planning. Their research adopted regression models similar to Varila et al. (2007).

The adoption of TDABC is also evident in areas other than logistics. In employee performance and resource allocation areas, TDABC is applied. Siguenza-Guzman, Den Abbeele, and Cattrysse (2014) and Siguenza-Guzman, Auquilla, Van den Abbeele, and Cattrysse (2016) reported cases on the application of TDABC in universities. The results indicated that TDABC was useful for tracing librarians' performance in the important and less important activities. They reported that resource allocation decisions were made based on the results.
Regarding the connection between employee performance and organizational performance, a proposal to relate the costing system to a Balanced Scorecard (BSC) emerges. Dwivedi and Chakraborty (2016) proposed integrating $\mathrm{ABC}$ into $\mathrm{BSC}$ as the costing system provided information regarding timedriven performance related to critical success factors under profitability targets.

In the activity costing and value-added activities area, Amiri and Khmidi (2019) mentioned that TDABC was beneficial for providing unused timedriven activity costing and supporting value-added activity decisions in a hospital in the United Arab Emirates. Similarly, Heaton et al. (2019) stated that the unused capacity time costs could be eliminated for an emergency unit operation in a hospital in the United States with the information provided by TDABC. In the hospitality industry, Basuki and Riediansyaf (2014) reported the integration of the costing system in calculating the costs of room divisions in a hotel.

TDABC in information technology-related activities is also an emerging concept. The costing system analytically can be the practical capacity in a manufacturing facility using advanced manufacturing Enterprise Resource Planning (ERP). Ganorkar, Lakhe, and Agrawal (2019) simulated the costing system using the ERP system called the Maynard Operation Sequence Technique (MOST) system. The simulation suggested that each activity cost was determined and adjusted using the costing system. These were possible due to the nature of the costing system focusing on total practical capacities and actual activities of critical activities. Furthermore, the MOST system facilitated the smooth implementation in the company studied.

Considering the applications and proposed models of TDABC, the costing system is applicable in different business settings/industries. It is beneficial for measuring different activity costs and assessing performance management with information technology as a potential factor for costing accuracy. TDABC is reportedly applicable to different business settings. Previous research mentioned has presented its application in wholesale, logistics, hospital, and hospitality industries. In the context of the Information and Communication Technology (ICT) industry, the research on the costing system and human capital planning is yet to be a focus.

The ICT industry is one of the fundamental bases of the growing knowledge-based economy. It creates major societal changes (Majchrzak, Markus, \& Wareham, 2016). Furthermore, the development of the information technology industry is a widespread development in developing countries. In India, the development of the ICT industry is a result of government, academic, and business collaborations that trigger the need for the industry cluster in the areas (Subrahmanya, 2017). It is argued that part of India's flourishing information technology industry is the availability of highly-skilled workforces as a 
result of mathematics and English familiarity in the education system (Kumar, 2017). The ICT industry is an economic growth opportunity for the country to manage its innovation settings nationally and workforces.

In Indonesia, the ICT industry has a high potential to develop. In terms of the use of the Internet as the backbone of ICT, Indonesia ranked the fifth in May 2019 (Internet World Stats, 2019). Since Internet use is the highest, the possibilities for further developing the ICT industry in Indonesia remains high. The population in Indonesia is around 260 million. More than $60 \%$ of the total population was within the working range as per United Nations data in 2015 and its prediction for 2020 (United Nations, 2019). Furthermore, in terms of ICT development, Indonesia is reported as a country with moderate development of ICT or ranks $19^{\text {th }}$ in Asia (International Telecommunication Union, 2017). Assuming that the working-age population is moderately active Internet users, the ICT industry market in Indonesia is huge. This assumption has been in sync with the prediction of Indonesia as the fastest growing internet economy from 2015 to 2018 in South East Asia, as stated by Anandan, Sipahimalani, Saini, Aryasomayajula, and Smittinet (2018).

ICT startups in Indonesia are developing to tap the potential market. Among major startup companies with international recognition, Indonesia's unicorn startups are Gojek, Traveloka, and Tokopedia (Mukti, Wibowo, \& Galih, 2019). In fact, from 992 startups in Indonesia, 460 of the companies are in the ICT industry. The number represented $46,4 \%$ of startup companies mapped in the 2019 report. The ICT startups are dispersed into e-commerce, financial technology, and gaming companies. Furthermore, based on the report, $73,42 \%$ of the companies have increased profitability (Zulfikar, 2018). This increased profitability indicates the viability of the companies in tapping Indonesia's huge ICT potential market.

Although the outlook of ICT potential market and the recent performance of ICT startups in Indonesia are promising, the challenges in product and market development remain. These challenges can be related to talent shortages and funding gaps concerning the prospective future of startups (DailySocial, 2018). The stated problem in the Dailysocial report is a talent shortage in programming. It can be a result of a missing efficiency performance tracing tool that can trace the value-added activities that absorb most of the productive time of programmers. Furthermore, the funding gap is related to the questionable future of startups. It can be based on concerns over costs and profitability.

The use of illustration in proposing a tool or a measurement is a common approach in the managerial accounting area. For example, in exploring the use of TDABC under uncertainty, Ostadi, Daloie, and Sepehri (2019) built and illustrated TDABC fuzzy model using the hospital as the setting. Moreover, theoretical approaches in proposing the use of a managerial accounting tool are also common. Feng and Ho (2016) proposed a theoretical model for the adoption of $\mathrm{ABC}$ and the discontinued adoption of $\mathrm{ABC}$. As the use of TDABC is undetectable in a small software startup in Indonesia, the descriptive illustration is essential for a basic understanding of future users.

There is a limited study on small/very small software development startups. Sánchez-Gordón and O'Connor (2016) studied a very small software development company process in developing software. They concluded the following processes applied in the company. First, it was the customer. There were customer satisfaction check, customer needs understanding, and customer expectation alignment. Second, software product involved requirement understanding, architecture design and selection, software build, software test, software deployment, and software operation. Third, coordination and tracking of development tasks consisted of activities coordination, progress tracking, and workflow end check. Fourth, in the software quality standards, they checked acceptance level, awareness on standard benefits, and adoption barriers.

Based on Sánchez-Gordón and O'Connor (2016), the fourth process is applied in the startup studied. However, it is yet to be a focus in the normal operation of the startup. The main challenges are time and talent availability. This research has similar concerns concerning time due to limited talents. Therefore, it includes only the first to the third processes in the TDABC illustration. The three processes are assumed to be strictly related to human capital in the illustration.

In exploring the application of $\mathrm{ABC}$ in a hospital, Chan (1993) presented an illustration to compare traditional and $\mathrm{ABC}$ results. Then, theoretical approaches in proposing the use of a managerial accounting tool is also a common approach. Stapleton, Pati, Beach, and Julmanichoti (2004) proposed the adoption of $\mathrm{ABC}$ for marketing and logistics using theoretical approach. As the use of TDABC is undetectable in small software startup companies in Indonesia while the descriptive illustration is important for basic understanding of future users, this research presents an illustration of time-driven $\mathrm{ABC}$ for performance and cost tracing systems.

The researchers propose TDABC as a costing system that can assist in minimizing the two problems in performance tracing and cost-tracing based on valueadded activities. The simulation method is applied for analyzing the potential of TDABC as the tool for performance and cost-tracing in the small software development startup. The small software development startup is an important context as there are limited discussions about software development small startup in product development (Giardino, Bajwa, Wang, \& Abrahamsson, 2015). Furthermore, small software development startup is prone to failures due to cost and schedule besides project cancellations and lost opportunities (Bajwa, Wang, Duc, \& Abrahamsson, 2017). Therefore, this is explorative research that 
enriches the current needed discourses on small software development startup using TDABC for performance and cost.

\section{METHODS}

The research adopts illustration as the qualitative method to assess and to propose time-driven $\mathrm{ABC}$ as a tool for performance and cost tracing. The illustration context is a small software development startup company. The use of illustration is necessary because first, the empirical studies within the ICT industry that involve the actual use of TDABC are lacking, and there is no secondary data to use. Second, published journal references for the use of TDABC in small software development startup is absent. Most studies on the companies are limited to development approaches and process challenges in the companies. Third, primary data needed for establishing TDABC from a small software development startup in Indonesia is possible after any actual $\mathrm{ABC}$ project is detectable, and actual data collection is permissible in that type of company in Indonesia.

The data for the illustration are the combination of regulation and assumed data. The regulation is related to work hours and the minimum wage. The base of the human capital cost is the regulated minimum wage in the special province area of Jakarta, Indonesia. Based on 2019 DKI Jakarta Governor Regulation No. 6, the amount is IDR 4.013.786 for a non-small to medium size software and application company. In terms of workforce, each process involves a diverse workforce except for the first and second processes. Furthermore, it is assumed that the second process is done after the first process is finished. Only the third process is done in parallel to the first and second processes.

\section{RESULTS AND DISCUSSIONS}

Based on Kaplan and Anderson (2007), TDABC starts with the determination of practical capacities. Then, the calculations of TDABC are based on the determined practical capacity. Practical capacity is different from theoretical capacity as it counts idle or miscellaneous activities that indirectly contribute to productivity or non-value adding for customers. There are several steps in conducting TDABC. First, the researchers determine the allocated practical capacities for the activity cost pool. Practical capacity is a certain percentage of theoretical capacity (Öker \& Adigüzel, 2010). This capacity is the denominator in the rate calculation of capacity cost. Second, the researchers see the capacity cost for the activity cost pool. These costs are summed up as the costs of allocated practical capacity. The resulting number is the rate calculation of capacity cost. Third, it calculates the capacity cost rate by using the numbers in the first and second steps.

Fourth, the researchers determine the allocated practical capacity for sub-activities in the activity cost pool. Fifth, it calculates the cost driver rate in each sub-activity in the activity cost pool by multiplying the result of the third and fourth steps. Sixth, the cost driver rate is assigned to trace the actual practical capacity. It is done by multiplying the result of the fifth step with the actual traced practical capacity. Seventh, the comparison is made between the used capacity and the unused capacity in terms of time units and costs to trace the performance and costs.

Implementing TDABC, the context of the illustration is a small software development startup. There are three processes considered in the illustration. There are related processes of the customer, product software, and coordination and tracking of development tasks. Under TDABC, the three processes can be treated as three activity cost pools. Table 1 describes the activity cost pools and the sub-activities.

Table 1 Activity Cost Pools and Sub-Activities

\begin{tabular}{ll}
\hline Activity Pool 1 (Customer) & $\begin{array}{l}\text { Customer satisfaction check } \\
\text { Customer needs understanding } \\
\text { Customer expectation } \\
\end{array}$ \\
\hline alignment \\
\hline Activity Pool 2 (Product & Requirement understanding \\
Software) & Architecture design and \\
& selection \\
& Software build \\
& Software test \\
& Software deployment \\
& Software operation \\
\hline Activity Pool 3 & Activities coordination \\
(Coordination and Tracking & Progress tracking \\
of Development Tasks) & Workflow end check \\
\hline
\end{tabular}

The calculations for the first to the seventh steps are described. The flow of the processes in Table 1 is sequential for the first and second processes. However, the third process is parallel to the first and second processes. Therefore, the following detailed calculation assumptions are applied in the calculations. First, theoretical capacity is the theoretical working time per day of 8 hours or 480 minutes per day or 28.800 minutes for a quarter of 60 days. Second, practical capacity is 6 hours after a deduction of 1,5 hours for lunch and 0,5 hours for miscellaneous activities. It is equal to 360 minutes per day or 21.600 minutes in a quarter of 60 days. Third, there are three working for presumably five actual projects (actual practical quantity) in one quarter. Two employees do the first and second processes sequentially while one person works in parallel during the first and second processes. Therefore, the total practical capacity in a quarter for three employees is 64.800 minutes. The number of projects in the calculation of practical capacity quantity for a quarter is 30 projects.

Fourth, the minimum wage in each day is IDR 200.689 or equal to IDR 52/minute. Fifth, the total estimated cost of practical capacity is IDR 703.314.084 for a total practical capacity of 64.800 
minutes in a quarter for three employees. There are five project developments in the quarter. Sixth, all numbers are rounded up or down using standard mathematical conventions. It is to ease the readings on IDR since cents are non-existent in IDR. Time is also rounded up or down when it is necessary to provide consistent ease of reading.

The practical capacity rate can be calculated since the total practical capacity is estimated and known (the first and second steps). The practical capacity rate is IDR 52 (the third step). The calculations can continue to the fourth step. Table 2 the results of the fourth and fifth steps. Moreover, for the sixth and seventh steps, it shows the assigned cost driver rate to the traced actual practical capacities and the comparison of the used and unused capacity. Table 3 presents the result. The rates assigned are from Table 2 .

Table 2 The Allocated Resources Practical Capacity to Sub-Activities and the Cost Driver Rate in Each Sub Activity

\begin{tabular}{lcc}
\hline Customer & $\begin{array}{c}\text { Minutes/sub- } \\
\text { activity }\end{array}$ & $\begin{array}{c}\text { Rate at IDR 52/ } \\
\text { Minute* }\end{array}$ \\
\hline $\begin{array}{l}\text { Customer satisfaction } \\
\text { check }\end{array}$ & 15 & 784 \\
$\begin{array}{l}\text { Customer needs } \\
\text { understanding }\end{array}$ & 60 & 3.136 \\
$\begin{array}{l}\text { Customer expectation } \\
\text { alignment }\end{array}$ & 10 & 523 \\
\hline
\end{tabular}

\begin{tabular}{|c|c|c|}
\hline Product Software & $\begin{array}{l}\text { Minutes/ sub- } \\
\text { activity }\end{array}$ & $\begin{array}{c}\text { Rate at IDR 52/ } \\
\text { Minute* }\end{array}$ \\
\hline $\begin{array}{l}\text { Requirement } \\
\text { understanding }\end{array}$ & 10 & 523 \\
\hline $\begin{array}{l}\text { Architecture design and } \\
\text { selection }\end{array}$ & 60 & 3.136 \\
\hline Software build & 600 & 31.358 \\
\hline Software test & 60 & 3.136 \\
\hline Software deployment & 60 & 3.136 \\
\hline Software operation & 60 & 3.136 \\
\hline $\begin{array}{l}\text { Coordination } \\
\text { and Tracking of } \\
\text { Development Tasks }\end{array}$ & $\begin{array}{l}\text { Minutes/sub- } \\
\text { activity }\end{array}$ & $\begin{array}{c}\text { Rate at IDR 52/ } \\
\text { Minute* }\end{array}$ \\
\hline Activities coordination & 60 & 3.136 \\
\hline Progress tracking & 60 & 3.136 \\
\hline Workflow end check & 60 & 3.136 \\
\hline
\end{tabular}

*contains round numbers

Comparing the unused and used capacity, there are two analytical conclusions. First, in terms of performance related to human capital or talents, the total time of used capacity based on the practical capacity is only about $10 \%$ for three employees in a quarter (6.525 minutes is divided by 64.800 minutes). Second, the actual assignment of practical capacity is equal to $15 \%$ of the total cost based on practical capacity (IDR 104.558.341 is divided by IDR 598.755.743).

Based on the results, a small startup can optimize its practical working time further. It should be the logical consequence as the practical capacity already reduce the amount of working time from the theoretical working time of eight hours. By having only six hours per day and assuming five software development projects, the team still has $90 \%$ of available time in the quarter. This calculation is based on the assumption that the five projects need 3.000 minutes in total (see Table 3 regarding software build). These total minutes can change tremendously based on the actual success of the team in building the software. If the team fails, the time to build software and other sub-activities in all activity cost pools will increase the actual time and costs.

Nevertheless, in terms of time, the increased actual time can still be within the practical capacity in a quarter. About $90 \%$ of the time practical capacity is available. When considering the adjusted actual costs due to failure, the increased time is a negative indication or a discrepancy since about $85 \%$ of the total practical capacity cost is unused. Therefore, the benefit of implementing TDABC in a software development small startup is beyond failure cost management.

There are two benefits to implement TDABC. First, it is in the area of project risk management in which time-related to human capital, talent availability, and costs are the constraints. A pro-active approach for the combination of talent and time in a small team is essential for minimizing risks. For example, the third process with one person deployed can be integrated into the first and second processes. The human resources can be assigned to the first and second processes in software test and customer satisfaction check. It can be a simultaneous process in the actual setting. This arrangement will minimize the risk of failure and increase customer satisfaction. The integration can also reduce costs due to the elimination of sub-activities.

The second benefit is related to human capital or talent acquisition planning. TDABC provides data regarding unused and used practical capacity. The unused practical capacity can indicate how many minutes are available from the current employees and whether it is necessary to acquire additional employees. The first and second potential benefits indicate the potential of TDABC to support both operational and strategic decision- making in cost management, human capital management, and talent acquisition. This potential can answer the lack of decision-making values of the older generation of $\mathrm{ABC}$, like Innes et al. (2000). The results are in line with the case studies about TDABC in large organizations such as hospitals helping in cost and time decision-making by Wouters and Stecher (2017). 
Table 3 The Cost Driver Rate Assignment to the Traced Actual Practical

Capacity and the Comparison of the Used and the Unused Capacity

\begin{tabular}{|c|c|c|c|}
\hline & $\begin{array}{c}\text { Actual Quantity in a } \\
\text { Quarter }\end{array}$ & Total Minutes & $\begin{array}{c}\text { Total Actual Cost/Sub-Activity } \\
\text { (IDR)* }\end{array}$ \\
\hline \multicolumn{4}{|c|}{ Customer } \\
\hline Customer satisfaction check & 5 & 75 & 58.796 \\
\hline Customer needs understanding & 5 & 300 & 940.731 \\
\hline Customer expectation alignment & 5 & 50 & 26.131 \\
\hline \multicolumn{4}{|c|}{ Product Software } \\
\hline Requirement understanding & 10 & 100 & 52.263 \\
\hline Architecture design and selection & 5 & 300 & 940.731 \\
\hline Software build & 5 & 3.000 & 94.073 .109 \\
\hline Software test & 10 & 600 & 1.881 .462 \\
\hline Software deployment & 5 & 300 & 940.731 \\
\hline Software operation & 5 & 300 & 940.731 \\
\hline \multicolumn{4}{|c|}{ Coordination and Tracking of Development Tasks } \\
\hline Activities coordination & 60 & 600 & 1.881 .462 \\
\hline Progress tracking & 60 & 600 & 1.881 .462 \\
\hline Workflow end check & 60 & 300 & 940.731 \\
\hline Used capacity & & 6.525 & 104.558 .341 \\
\hline Unused capacity & & 58.275 & 598.755 .743 \\
\hline Total & & 64.800 & 703.314.084 \\
\hline
\end{tabular}

\section{CONCLUSIONS}

TDABC can support operational and strategic decision making in cost management, human capital management, and talent acquisition. These three operational and strategic decision-making are parts of performance evaluation and project risk management. The potential can answer the lack of decision-making values of the older generation of ABC. Furthermore, TDABC using the simulated data processes in a small software development startup analytically shows the feasibility of applying the simplified version of $A B C$ in any small software development startup in Indonesia.

The illustration of TDABC can benefit the complex development process as it can show the unused or overused practical capacities. Thus, a strategic human capital optimization and cost planning can be based on the adjusted illustration. The optimization simulation can also help to manage error estimations and allocation, or application of constraints in large or complex projects/organizations aiming to apply TDABC. Furthermore, as this study uses a small software development startup as the illustration setting, the interpretation of the results is limited to the setting and data applied.

Further research can illustrate the application of TDABC in different settings of the software development processes in a medium or large-size software development company. For example, an agile artifact-based process in a complex software development involving off-shore teams requires the adoption of agile culture, ceremonies, and artifacts mapping as described in Bass (2016). The illustration of time-driven $\mathrm{ABC}$ can benefit the complex development process as it can show the unused or overused practical capacities. Thus, a strategic human capital optimization and cost planning can be based on the adjusted illustration.

\section{REFERENCES}

Afonso, P., \& Santana, A. (2016). Application of the TDABC model in the logistics process using different capacity cost rates. Journal of Industrial Engineering and Management (JIEM), 9(5), 10031019.

Amiri, N., \& Khmidi, S. (2019). Implementing Time-Driven Activity-Based Costing (TDABC) in out-patient nursing department: A case from UAE. Management Science Letters, 9(3), 365-380.

Anandan, R., Sipahimalani, R., Saini, S., Aryasomayajula, S., \& Smittinet, W. (2018). E-conomy SEA 2018: Southeast Asia's Internet economy hits an inflection point. Retrieved May 1st, 2019 from https:// www.thinkwithgoogle.com/intl/en-apac/futureof-marketing/digital-transformation/e-conomysea-2018-southeast-asias-internet-economy-hitsinflection-point//

Bajwa, S. S., Wang, X., Duc, A. N., \& Abrahamsson, P. (2017). "Failures" to be celebrated: An analysis 
of major pivots of software startups. Empirical Software Engineering, 22(5), 2373-2408.

Bass, J. M. (2016). Artefacts and agile method tailoring in large-scale offshore software development programmes. Information and Software Technology, 75(July), 1-16.

Basuki, \& Riediansyaf, M. D. (2014). The application of time driven activity based costing in the hospitality industry: An exploratory case study. The Journal of Applied Management Accounting Research (JAMAR), 12(1), 27-54.

Bromwich, M., \& Hong, C. (1999). Activity-based costing systems and incremental costs. Management Accounting Research, 10(1), 39-60.

Chan, Y. C. (1993). Improving hospital cost accounting with activity-based costing. Health Care Management Review, 18(1), 71-77.

DailySocial. (2018). Laporan DailySocial: Startup report 2018. Retrieved May 1 ${ }^{\text {st }}, 2019$ from https:// dailysocial.id/post/startup-report-2018

Dwivedi, R., \& Chakraborty, S. (2016). Development of a strategic management tool in a thermal power plant using ABC and BSC models. Serbian Journal of Management, 11(1), 81-97.

Feng, S., \& Ho, C. Y. (2016). The real option approach to adoption or discontinuation of a management accounting innovation: The case of activity-based costing. Review of Quantitative Finance and Accounting, 47(3), 835-856.

Ganorkar, A. B., Lakhe, R. R., \& Agrawal, K. N. (2019). Methodology for application of Maynard Operation Sequence Technique (MOST) for Time-Driven Activity-Based Costing (TDABC). International Journal of Productivity and Performance Management, 68(1), 2-25.

Giardino, C., Bajwa, S. S., Wang, X., \& Abrahamsson, P. (2015). Key challenges in early-stage software startups. In International Conference on Agile Software Development (pp. 52-63).

Heaton, H. A., Nestler, D. M., Barry, W. J., Helmers, R. A., Sir, M. Y., Goyal, D. G., ... \& Sadosty, A. T. (2019). A time-driven activity-based costing analysis of emergency department scribes. Mayo Clinic Proceedings: Innovations, Quality \& Outcomes, 3(1), 30-34.

Hofmann, E., \& Bosshard, J. (2017). Supply chain management and activity-based costing. International Journal of Physical Distribution \& Logistics Management, 47(8), 712-735.

Innes, J., \& Mitchell, F. (1995). A survey of activity-based costing in the UK's largest companies. Management Accounting Research, 6(2), 137-153.

Innes, J., Mitchell, F., \& Sinclair, D. (2000). Activity-based costing in the UK's largest companies: A comparison of 1994 and 1999 survey results. Management Accounting Research, 11(3), 349-362.

International Telecommunication Union. (2017). Measuring the information society report 2017. Retrieved July $1^{\text {st }}, 2019$ from www.itu.int/en/ITU-D/Statistics/ Pages/publications/mis2017.aspx

Internet World Stats. (2019). Top Internet usage. Retrieved
May 1 ${ }^{\text {st }}, 2019$ from https://internetworldstats.com/ top20.htm

Ittner, C. D. (1999). Activity-based costing concepts for quality improvement. European Management Journal, 17(5), 492-500.

Jeong, J. Y., \& Ahn, K. M. (2015). A case study on costing management of a logistics warehouse in port distri-park by time-driven $\mathrm{ABC}$ and contribution margin analysis. Journal of Korea Port Economic Association, 31(3), 167-186.

Johnson, S., \& Brennan, P. (2018). Northflow Solutions, Inc.: Using $\mathrm{ABC}$ to create a new pricing model. Journal of Case Studies, 36(2), 108-114.

Kaplan, R. S., \& Anderson, S. R. (2007). Time-driven activity-based costing: A simpler and more powerful path to higher profits. USA: Harvard Business School Publishing Corporation.

Kumar, A. (2017). Information technology industry. Journal of Management Science, Operations \& Strategies, $1(1), 12-5$.

Malmi, T. (1999). Activity-based costing diffusion across organizations: An exploratory empirical analysis of Finnish firms. Accounting, organizations and society, 24(8), 649-672.

Majchrzak, A., Markus, M. L., \& Wareham, J. (2016). Designing for digital transformation: Lessons for information systems research from the study of ICT and societal challenges. MIS Quarterly, 40(2), 267277.

Martínez-Vivar, R., Sánchez-Rodríguez, A., PérezCampdesuñer, R., \& García-Vidal, G. (2018). Contribution to the logistic evaluation system in the transportation process in Santo Domingo, Ecuador. Journal of Industrial Engineering and Management (JIEM), 11(1), 72-86.

Mukti, I. Y., Wibowo, A. P. W., \& Galih, S. (2019). Lessons learned to increase the digital startups success rate. Global Business \& Management Research, 11(1), 226-234.

Öker, F., \& Adigüzel, H. (2010). Time-driven activity-based costing: An implementation in a manufacturing company. Journal of Corporate Accounting \& Finance, 22(1), 75-92.

Ostadi, B., Daloie, R. M., \& Sepehri, M. M. (2019). A combined modelling of fuzzy logic and Time-Driven Activity-based Costing (TDABC) for hospital services costing under uncertainty. Journal of Biomedical Informatics, 89(January), 11-28.

Ratnatunga, J., Michael, S. C., \& Balachandran, K. R. (2012). Cost management in Sri Lanka: A case study on volume, activity and time as cost drivers. The International Journal of Accounting, 47(3), 281-301.

Sánchez-Gordón, M. L., \& O’Connor, R. V. (2016). Understanding the gap between software process practices and actual practice in very small companies. Software Quality Journal, 24(3), 549-570.

Siguenza-Guzman, L., Den Abbeele, A. V., \& Cattrysse, D. (2014). Time-driven activity-based costing systems for cataloguing processes: A case study. Liber Quarterly: The Journal of European Research Libraries, 23(3), 160-186. 
Siguenza-Guzman, L., Auquilla, A., Van den Abbeele, A., \& Cattrysse, D. (2016). Using Time-Driven Activity Based Costing to identify best practices in academic libraries. The Journal of Academic Librarianship, 42(3), 232-246.

Stapleton, D., Pati, S., Beach, E., \& Julmanichoti, P. (2004). Activity-based costing for logistics and marketing. Business Process Management Journal, 10(5), 584597.

Subrahmanya, M. B. (2017). Comparing the entrepreneurial ecosystems for technology startups in Bangalore and Hyderabad, India. Technology Innovation Management Review, 7(7), 47-62.

United Nations. (2019). Population data. Retrieved July $1^{\text {st }}$, 2019 from https://population.un.org/wpp/Download/ Standard/Population/

Varila, M., Seppänen, M., \& Suomala, P. (2007). Detailed cost modelling: A case study in warehouse logistics. International Journal of Physical Distribution \& Logistics Management, 37(3), 184-200.

Wouters, M., \& Stecher, J. (2017). Development of real-time product cost measurement: A case study in a mediumsized manufacturing company. International Journal of Production Economics, 183, 235-244.

Zulfikar, R. (2018). Mapping and database startup Indonesia 2018. Retrieved from https://www.bekraf. go.id/pustaka/page/mapping-database-startupindonesia-2018 